\title{
The combined effect of employment status and transcultural marriage on breast feeding: a population-based survey in Taiwan
}

\author{
Chao-Hua Chuang ${ }^{a, b}$, Pei-Jen Chang ${ }^{c}$, Wu-Shiun Hsieh ${ }^{d}$, Yueliang Leon Guo ${ }^{e}$, Shu-Hui Linf, Shio-Jean Lin ${ }^{g}$ and \\ Pau-Chung Chen ${ }^{\mathrm{a}}$ \\ ${ }^{a}$ Institute of Occupational Medicine and Industrial Hygiene, National Taiwan University College of Public Health, Taipei, ${ }^{b}$ Department of \\ Nursing, Fooyin University, Kaohsiung County, 'Department of Nursing, National Taipei College of Nursing, Taipei, Departments of \\ ${ }^{d}$ Paediatrics and ${ }^{e}$ Environmental and Occupational Medicine, National Taiwan University Hospital and National Taiwan University College of

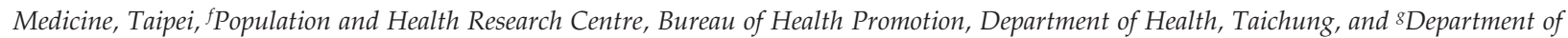 \\ Paediatrics, National Cheng-Kung University Hospital and College of Medicine, National Cheng-Kung University, Tainan, Taiwan
}

Correspondence:

Dr Pau-Chung Chen, Institute of Occupational Medicine and Industrial Hygiene, National Taiwan University College of Public Health, 17, Syujhou Road, Taipei 100, Taiwan. E-mail: pchen@ntu.edu.tw

\section{Summary}

Chuang C-H, Chang P-J, Hsieh W-S, Guo YL, Lin S-H, Lin S-J, Chen P-C. The combined effect of employment status and transcultural marriage on breast feeding: a population-based survey in Taiwan. Paediatric and Perinatal Epidemiology 2007; 21: 319-329.

In recent decades there has been a marked rise in both the labour market participation of women with infants and transcultural marriage in Taiwan. The objectives of this study were to explore the combined effect of employment status and transcultural marriage on the prevalence and factors relating to initiation and continuation of breast feeding in Taiwan. We used multistage stratified systematic sampling to recruit 2048 postpartum women from the Taiwan National Birth Registration database for the period November to December 2003. They were interviewed at home within 6 months of delivery using a structured questionnaire; $87 \%$ of the sampled population completed the interview. We used logistic regression analysis to estimate the odds ratio (OR) of breast-feeding initiation and Cox regression (survival) analysis to predict continued breast feeding.

The prevalences of initial breast feeding for employed Taiwanese mothers, unemployed Taiwanese mothers, employed foreign-born mothers and unemployed foreignborn mothers were $84.4 \%, 83.7 \%, 79.1 \%$ and $79.7 \%$, respectively. Among the four groups of mothers who initiated breast feeding, $12.9 \%, 27.2 \%, 14.7 \%$ and $39.7 \%$ of their infants, respectively, were still breast feeding at the age of 6 months. Factors associated with initiation of breast feeding were high maternal education (OR 3.80; 95\% confidence interval [CI] 1.81, 7.98) and normal spontaneous delivery (OR 1.36; 95\% CI 1.04, 1.78). The main reason for not breast feeding in $52 \%$ of the mothers was insufficient or no milk. There existed a combined effect of employment status and transcultural marriage on the continuation of breast feeding. Employed Taiwanese mothers were earlier than others at weaning. Unemployed foreign-born mothers breast fed the longest [hazard ratio (HR) $0.54 ; 95 \%$ CI $0.42,0.70$ ]. Other factors related to late weaning were high maternal education (HR 0.67; 95\% CI 0.47, 0.96), older maternal age (HR 0.76; $95 \%$ CI $0.61,0.94)$, mother sleeping with baby at night (HR $0.68 ; 95 \%$ CI $0.59,0.78$ ), and no supplemental baby food before the age of 6 months (HR 0.78; 95\% CI 0.68, 0.90).

The initiation of breast feeding was high but it decreased dramatically after the postpartum period in Taiwan. There was a significant combined effect of employment status and transcultural marriage on the continuation of breast feeding. Employment is a persistent barrier to continued breast feeding.

Keywords: breast feeding, maternal employment, transcultural marriage. 


\section{Introduction}

Breast feeding has been recognised worldwide for its health benefits such as a reduced risk of use of health services, ${ }^{1}$ postnatal death, ${ }^{2}$ acute respiratory infection and diarrhoeal deaths, ${ }^{3}$ child asthma and atopy, ${ }^{4}$ overweight children ${ }^{5}$ and atherosclerosis. ${ }^{6}$ Successful breast feeding depends on multiple factors relating to the parents, infants and the supporting environment. They include socio-demographic (ethnicity, maternal age, education, employment), biomedical (maternal overweight and obesity, type of delivery and infant diseases), related health system services (rooming-in facilities, feeding on demand and prenatal classes), psychosocial and cultural determinants, and the pattern of breast feeding (the quantity of milk, early introduction of mixed or supplemental feeding)..$^{-12}$

In recent decades there has been a marked rise in the labour market participation of women with infants in many countries. The Taiwanese female labour force participation in 1978 was $39 \%$; by 2002 it had risen to $51 \% .{ }^{13}$ Breast feeding has been consistently associated with physical, psychological, social, economic and nutritional benefits to mothers and infants, but return to work represents a substantial hurdle for working mothers to continue to breast feed. ${ }^{14,15}$ Growing research literature highlights the negative effect of employment status on breast-feeding initiation ${ }^{16}$ and duration. ${ }^{17}$

Recently in Taiwan the prevalence of transcultural marriage has been steadily increasing. In the 2003 marriage statistics, about $28 \%$ of brides were not born in Taiwan. ${ }^{18}$ At the same time, about $13 \%$ of infants were born to foreign-born women. Different race or ethnicity may affect patterns of breast feeding, ${ }^{19,20}$ so analysis of differences in the prevalence of breast-feeding initiation and continuation in transcultural marriages may provide information about practices that encourage breast feeding. The purpose of this study was to explore the combined effect of employment status and transcultural marriage on the prevalence and risk factors for the initiation and continuation of breast feeding in Taiwan.

\section{Methods}

\section{Study population and sampling strategy}

This research is based upon a prospective longitudinal cohort study design. We used the multistage stratified systematic sampling design to obtain the samples from the Taiwan national birth registration data for the period November to December 2003. A total of 369 towns in Taiwan were ranked into 12 strata according to the administrative division (four strata) and the total fertility rate (three strata). Using the principle of proportion probability to size, we randomly sampled 29 towns from the 12 strata (Fig. 1). All postpartum women and newborns, a total of 2048 pairs, from these 29 towns were recruited. All study participants provided informed consent previously as approved by the Ethics Review Board of the National Taiwan University College of Public Health.

\section{Data collection}

The parents' and infants' basic demographic information was abstracted from the Taiwan national birth registration data. We then conducted a home interview with the 2048 postpartum women within 6 months after delivery using a structured questionnaire in the period from April to June 2004. There were 265 cases of loss of follow-up because of refusal to participate $(n=144)$, moving home $(n=42)$, incorrect addresses $(n=35)$, going abroad $(n=20)$, infant deaths $(n=14)$, adopted infants $(n=3)$ and other miscellaneous reasons $(n=7)$. A total of 1783 postpartum women were interviewed, giving a completed interview rate of $87 \%$.

\section{Variables}

Data were obtained from the Taiwan national birth registry and the interview questionnaire. Variables related to breast feeding included the initiation and duration. Breast feeding was defined as including mixed and exclusive breast feeding. The duration of breast feeding was stratified into seven groups: $<1 ; 1$ to $<2 ; 2$ to $<3 ; 3$ to $<4 ; 4$ to $<5 ; 5$ to $<6$; and $6+$ months. The major reason for never breast feeding was also asked by one open question and then grouped into the reasons as shown in Table 6.

Information on maternal occupation was collected including 1 year before the current pregnancy, and during the pregnancy and postpartum periods. Maternal employment was defined either as mothers returning to work after maternity leave, or they did not work during pregnancy but worked after delivery. The classification of maternal occupation was based on the Taiwan version of the International Classification of 


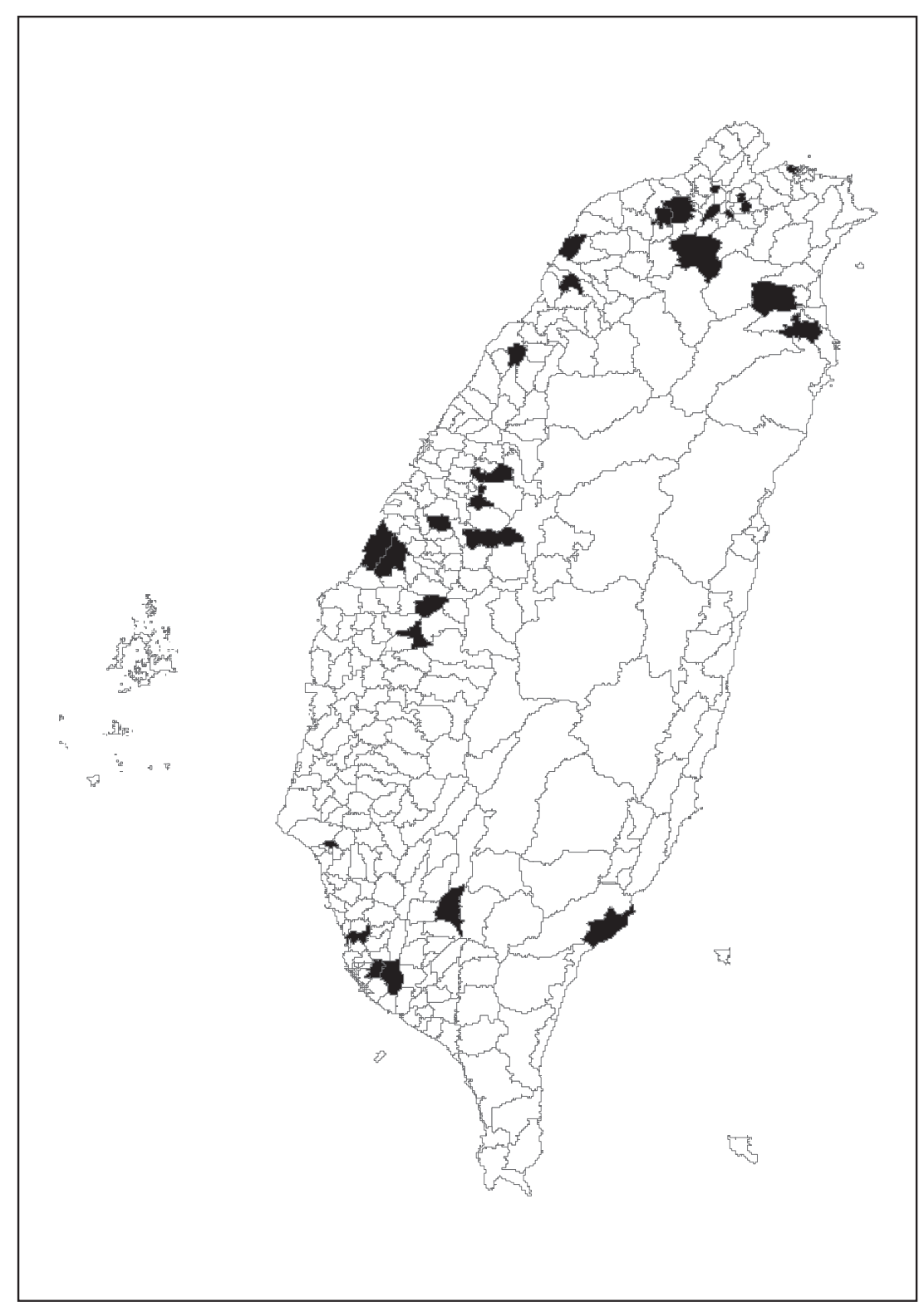

Figure 1. Random sampling of 29 towns (in black) out of 369 in Taiwan.

Occupations, which was later summarised into two groups: employed and unemployed. Mothers were grouped into Taiwanese mothers and foreign-born mothers whose home country was not Taiwan (e.g. Vietnam, China, Indonesia, Cambodia, Thailand, Malaysia, Myanmar). The classification of a combined effect of employment status and transcultural marriage was stratified into four groups: employed Taiwanese mothers, unemployed Taiwanese mothers, employed foreign-born mothers and unemployed foreign-born mothers.

The population of mothers was grouped by age: $\leq 19$, 20-34 and 35+ years. Their educational levels were stratified into four groups: university and college or above, senior high school, junior high school and elementary or below. Family income per year was defined as the total parental income per year within four categories in new Taiwan dollars (NT\$, 1 US $\$ \approx 32$ NT\$, in 2005): $\leq 390 \mathrm{k}, 400 \mathrm{k}-590 \mathrm{k}, 600 \mathrm{k}-990 \mathrm{k}$ and $1000 \mathrm{k}$ or more. Place of residence was classified as urban areas, town centres in rural areas and rural areas. Parity was grouped into 0,1 and 2 . There were three groups of maternal weight gain during pregnancy: $<10,10-19$ and $20+\mathrm{kg}$. The types of delivery were normal spontaneous delivery and caesarean section. Variables relating to infants included gender, 
preterm delivery, neonatal jaundice and allergic dermatitis. The pattern of nurturing included supplemental baby-food feeding before age 6 months, mother sleeping with the baby at night, mother living with the baby (days per week) and major caregivers. There were three groups of number of days per week that mothers lived with the baby ( $\leq 3,4-6$ and 7 days) and four groups (parents, grandparents, parents and grandparents and babysitters) of major caregivers.

\section{Statistical analysis}

Chi-square was performed to test the difference of basic characteristics and potential risk factors within four groups. Multiple logistic regressions were performed to estimate odds ratios (OR) and their 95\% confidence intervals $[\mathrm{CI}]$ of the dichotomous initial breast-feeding outcomes in four groups after adjusting for potential confounding of demographics (maternal age, education, family income per year, place of residence, parity, gender of infant) and other factors (maternal weight gain in pregnancy, type of delivery, neonatal jaundice, preterm delivery, mother sleeping with the baby at night). To predict continuation of breast feeding in four groups, Cox regression analysis was used to estimate hazard ratios (HR) and their 95\% CI after adjusting for potential confounders listed above. Potential confounders included in the final model of the multiple logistic regression and the Cox regression included information from previous studies and the $10 \%$ change-in-estimate method. ${ }^{21}$ This method selects a variable for control only if its inclusion produces more than a $10 \%$ change in the ratio estimate of interest. The statistical analyses were performed using sPSs for Windows, Release 11.0.

\section{Results}

The characteristics of 265 non-responders and 1783 responders are compared in Table 1 . The mean maternal and paternal ages were 28.4 and 32.4 years, respectively, in the non-respondent group, similar to that of the respondents. The mean infant birthweight and gestational week were $3046.8 \mathrm{~g}$ and 38.0 weeks in the non-responders, and $3096.9 \mathrm{~g}$ and 38.4 weeks in the respondents, respectively. There were no significant differences in the characteristics between the nonresponders and the responders, concerning parents' age, birthweight, gender, or low birthweight of newborns. The prevalence of preterm births was, however, slightly higher in non-responders $(12.1 \%)$ than in responders $(8.3 \%)$.

The characteristics of the subjects are summarised in Tables 2 and 3. Most of the subjects were aged 20-34 years old $(87.6 \%)$. Those with a senior high school education $(60.9 \%)$ predominated, half resided in urban areas (50.5\%) and $34.4 \%$ of the families had an annual income of 600 k-990 k NT\$. About half of the mothers were primiparous $(51.1 \%)$ and $55.3 \%$ of the infants were male. Comparison of Taiwanese and foreign-born mothers showed the latter to be less likely to be aged 35+ years, to be more likely to be multiparae, to have lower education level and family income and be more likely to live in rural areas.

Most women increased 10-19 kg during pregnancy $(70.2 \%)$, and had normal spontaneous delivery $(66.0 \%)$. Most infants were not delivered preterm $(91.7 \%)$, had no neonatal jaundice (53.5\%) and no allergic dermatitis $(86.7 \%)$. Over $80 \%$ of mothers slept (80.1) and lived $(87.0 \%)$ with their babies 7 days per week, and parents were the major caregivers (50.4\%); $75.3 \%$ of babies had been fed supplemental baby food before
Table 1. Comparison of characteristics between lost to follow-up $(n=265)$ and follow-up group $(n=1783)$

\begin{tabular}{lccc}
\hline Characteristics & $\begin{array}{c}\text { Lost to follow-up } \\
\text { (non-responders) }\end{array}$ & $\begin{array}{c}\text { Follow-up } \\
\text { (responders) }\end{array}$ & $P$-value \\
\hline Parents & & & \\
$\quad$ Mean maternal ages (years) & 28.4 & 28.4 & 0.99 \\
$\quad$ Mean paternal ages (years) & 32.4 & 32.4 & 0.95 \\
Infants & & & \\
Mean birthweight (g) & 3046.8 & 3096.9 & 0.19 \\
Mean gestation (weeks) & 38.0 & 38.4 & 0.01 \\
Male gender of infants & $52.8 \%$ & $55.0 \%$ & 0.50 \\
Singleton & $97.7 \%$ & $96.8 \%$ & 0.60 \\
Low birthweight & $9.1 \%$ & $7.0 \%$ & 0.23 \\
Preterm delivery & $12.1 \%$ & $8.3 \%$ & 0.04 \\
\hline
\end{tabular}


Table 2. Characteristics of study subjects

\begin{tabular}{|c|c|c|c|c|c|c|}
\hline \multirow[b]{2}{*}{ Characteristics } & \multirow[b]{2}{*}{ Total } & \multicolumn{2}{|c|}{ Taiwanese mothers } & \multicolumn{2}{|c|}{ Foreign-born mothers } & \multirow[b]{2}{*}{$P$-value } \\
\hline & & Employed & Unemployed & Employed & Unemployed & \\
\hline Total $(=100 \%)$ & 1783 & 972 & 566 & 43 & 202 & \\
\hline \multicolumn{7}{|l|}{ Maternal age (years) } \\
\hline$<20$ & $60(3.4)$ & $15(1.5)$ & $36(6.4)$ & $2(4.7)$ & $7(3.5)$ & $<0.001$ \\
\hline $20-34$ & $1562(87.6)$ & $856(88.1)$ & $478(84.5)$ & $41(95.3)$ & $187(92.6)$ & \\
\hline $35+$ & $161(9.0)$ & $101(1.4)$ & $52(9.2)$ & $0(0.0)$ & $8(4.0)$ & \\
\hline \multicolumn{7}{|l|}{ Maternal education } \\
\hline Elementary school - & $105(5.9)$ & $5(0.5)$ & $12(2.1)$ & $20(46.5)$ & $68(33.7)$ & $<0.001$ \\
\hline Junior high school & $259(14.5)$ & $76(7.8)$ & $93(16.4)$ & $16(37.2)$ & $74(36.6)$ & \\
\hline Senior high school & $1085(60.9)$ & $622(64.0)$ & $403(71.2)$ & $6(14.0)$ & $54(26.7)$ & \\
\hline University + & $334(18.7)$ & $269(27.7)$ & $58(10.2)$ & $1(2.3)$ & $6(3.0)$ & \\
\hline \multicolumn{7}{|c|}{ Family income per year (NT\$) } \\
\hline$\leq 390 \mathrm{k}$ & $377(21.1)$ & $86(8.8)$ & $176(31.1)$ & $22(51.2)$ & $93(46.0)$ & $<0.001$ \\
\hline $400 \mathrm{k}-590 \mathrm{k}$ & $374(21.0)$ & $132(13.6)$ & $168(29.7)$ & $9(20.9)$ & $65(32.2)$ & \\
\hline $600 \mathrm{k}-990 \mathrm{k}$ & $613(34.4)$ & $393(40.4)$ & $171(30.2)$ & $10(23.3)$ & $39(19.3)$ & \\
\hline $1000+\mathrm{k}$ & $419(23.5)$ & $361(37.1)$ & $51(9.0)$ & $2(4.7)$ & $5(2.5)$ & \\
\hline \multicolumn{7}{|l|}{ Place of residence } \\
\hline Urban area & $901(50.5)$ & $527(54.2)$ & $273(48.2)$ & $14(32.6)$ & $87(43.1)$ & 0.001 \\
\hline Town of rural area & $365(20.5)$ & $200(20.6)$ & $116(20.5)$ & $12(27.9)$ & 37 (18.3) & \\
\hline Rural area & $517(29.0)$ & $245(25.2)$ & 177 (31.3) & $17(39.5)$ & $78(38.6)$ & \\
\hline \multicolumn{7}{|l|}{ Parity } \\
\hline 0 & $912(51.1)$ & $521(53.6)$ & $258(45.6)$ & $21(48.8)$ & $112(55.4)$ & $<0.001$ \\
\hline 1 & $670(37.6)$ & 349 (35.9) & $219(38.7)$ & $18(41.9)$ & $84(41.6)$ & \\
\hline $2+$ & $201(11.3)$ & $102(10.5)$ & 89 (15.7) & $4(9.3)$ & $6(3.0)$ & \\
\hline \multicolumn{7}{|l|}{ Gender of infant } \\
\hline Male & $986(55.3)$ & $540(55.6)$ & $314(55.5)$ & $20(46.5)$ & $112(55.4)$ & 0.711 \\
\hline Female & $797(44.7)$ & $432(44.4)$ & $252(44.5)$ & $23(53.5)$ & $90(44.6)$ & \\
\hline
\end{tabular}

Values in parentheses are percentages.

6 months old. Comparison of the two groups shows that foreign-born mothers had lower weight gain during pregnancy, were more likely to have a spontaneous delivery, and to sleep with their babies than Taiwanese-born mothers.

Prevalence rates of breast feeding are shown in Table 4. The overall prevalence rate of initial breast feeding was $83.5 \%$. There was no significant difference among employed Taiwanese mothers $(84.4 \%)$, unemployed Taiwanese mothers (83.7\%), employed foreignborn mothers $(79.1 \%)$ and unemployed foreign-born mothers $(79.7 \%)$. Overall, of the mothers who had initiated breast feeding $50.2 \%$ and $20.4 \%$ still breast fed their infants at the ages of 1 and 6 months, respectively. There was a significant difference in the prevalence of continued breast feeding among the four groups: $12.9 \%, 27.2 \%, 14.7 \%$ and $39.7 \%$ of employed Taiwanese mothers, unemployed Taiwanese mothers, employed foreign-born mothers and unemployed foreign-born mothers who initially breast fed their infants were still breast feeding at the age of 6 months, respectively. The monthly prevalence of continued breast feeding for mothers who initiated breast feeding is shown in Fig. 2.

Factors significantly related to breast-feeding initiation are shown in Table 5. After adjustment for maternal education, type of delivery and preterm delivery the ORs of initial breast feeding still showed no significant difference between the four groups of mothers.

Reasons for never breast feeding are shown in Table 6. The major reason for most mothers who never initiated breast feeding was insufficient or no milk $(52.0 \%)$. Secondary reasons were that breast feeding was inconvenient for returning to work and that formula was more convenient than breast feeding $(15.3 \%)$.

Factors affecting the continuation of breast feeding are shown in Table 7. After adjustment for maternal 
Table 3. Factors related to breast feeding

\begin{tabular}{|c|c|c|c|c|c|c|}
\hline \multirow[b]{2}{*}{ Factors } & \multirow[b]{2}{*}{ Total } & \multicolumn{2}{|c|}{ Taiwanese mothers } & \multicolumn{2}{|c|}{ Foreign-born mothers } & \multirow[b]{2}{*}{$P$-value } \\
\hline & & Employed & Unemployed & Employed & Unemployed & \\
\hline Total $(=100 \%)$ & 1783 & 972 & 566 & 43 & 202 & \\
\hline \multicolumn{7}{|l|}{ Maternal factors } \\
\hline \multicolumn{7}{|l|}{ Weight gain during pregnancy $(\mathrm{kg})$} \\
\hline$<10$ & $256(14.4)$ & $122(12.6)$ & $87(15.4)$ & $9(20.9)$ & $38(18.8)$ & 0.003 \\
\hline $10-19$ & $1252(70.2)$ & $694(71.4)$ & $379(67.0)$ & $32(74.4)$ & $147(72.8)$ & \\
\hline $20+$ & $275(15.4)$ & $156(16.0)$ & $100(17.7)$ & $2(4.7)$ & $17(8.4)$ & \\
\hline \multicolumn{7}{|l|}{ Type of delivery } \\
\hline Normal spontaneous delivery & $1176(66.0)$ & $613(63.1)$ & $379(67.0)$ & $36(83.7)$ & $148(73.3)$ & 0.002 \\
\hline Caesarean section & $607(34.0)$ & $359(36.9)$ & $187(33.0)$ & 7 (16.3) & $54(26.7)$ & \\
\hline \multicolumn{7}{|l|}{ Infant factors } \\
\hline \multicolumn{7}{|l|}{ Preterm delivery } \\
\hline No & 1635 (91.7) & $894(92.0)$ & $511(90.3)$ & $43(100.0)$ & $187(92.6)$ & 0.128 \\
\hline Yes & $148(8.3)$ & $78(8.0)$ & $55(9.7)$ & - & $15(7.4)$ & \\
\hline \multicolumn{7}{|l|}{ Neonatal jaundice } \\
\hline No & $954(53.5)$ & $534(54.9)$ & $296(52.3)$ & $18(41.9)$ & $106(52.5)$ & 0.312 \\
\hline Yes & $829(46.5)$ & $438(45.1)$ & $270(47.7)$ & $25(58.1)$ & $96(47.5)$ & \\
\hline \multicolumn{7}{|l|}{ Allergic dermatitis } \\
\hline No & 1545 (86.7) & $830(85.4)$ & $486(85.9)$ & $43(100.0)$ & $186(92.1)$ & 0.004 \\
\hline Yes & $238(13.3)$ & $142(14.6)$ & $80(14.1)$ & - & $16(7.9)$ & \\
\hline \multicolumn{7}{|l|}{ Nursery patterns } \\
\hline \multicolumn{7}{|l|}{$\begin{array}{l}\text { Supplemental baby-food feeding } \\
\text { before age of } 6 \text { months }\end{array}$} \\
\hline No & $441(24.7)$ & $228(23.5)$ & $132(23.3)$ & $15(34.9)$ & $66(32.7)$ & 0.014 \\
\hline Yes & $1342(75.3)$ & $744(76.5)$ & $434(76.7)$ & $28(65.1)$ & $136(67.3)$ & \\
\hline \multicolumn{7}{|l|}{ Mother sleeping with the baby } \\
\hline No & 354 (19.9) & 307 (31.6) & $33(5.8)$ & $6(14.0)$ & $8(4.0)$ & $<0.001$ \\
\hline Yes & $1429(80.1)$ & $665(68.4)$ & $533(94.2)$ & $37(86.0)$ & $194(96.0)$ & \\
\hline \multicolumn{7}{|l|}{$\begin{array}{l}\text { Mother living with the baby } \\
\text { (days per week) }\end{array}$} \\
\hline$<4$ & 206 (11.6) & $190(19.5)$ & $12(2.1)$ & $4(9.3)$ & - & $<0.001$ \\
\hline $4-6$ & $25(1.4)$ & $21(2.2)$ & $3(0.5)$ & $1(2.3)$ & - & \\
\hline 7 & $1554(87.0)$ & $761(78.3)$ & $551(97.3)$ & $38(88.4)$ & $202(100.0)$ & \\
\hline \multicolumn{7}{|l|}{ Major caregiver } \\
\hline Parents & $898(50.4)$ & $249(25.6)$ & $462(81.6)$ & $19(44.2)$ & $168(83.2)$ & $<0.001$ \\
\hline Grandparents & $366(20.5)$ & $340(35.0)$ & $14(2.5)$ & $9(20.9)$ & $3(1.5)$ & \\
\hline Parents and grandparents & $382(21.4)$ & $253(26.0)$ & $87(15.4)$ & $13(30.2)$ & $29(14.4)$ & \\
\hline Babysitter & $137(7.7)$ & $130(13.4)$ & $3(0.5)$ & $2(4.7)$ & $2(1.0)$ & \\
\hline
\end{tabular}

Values in parentheses are percentages.

education, maternal age, mother sleeping with baby at night and supplemental baby-food feeding before the age of 6 months, employed Taiwanese mothers were significantly earlier in weaning than the other groups (unemployed Taiwanese mothers: HR 0.76; 95\% CI 0.66, 0.88; employed foreign-born mothers: HR 0.91; 95\% CI 0.60, 1.37; unemployed foreign-born mothers: HR 0.54; 95\% CI 0.42, 0.70, compared with employed Taiwanese mothers).

\section{Discussion}

Our study has shown that the initiation of breast feeding was common but the continuation of breast feeding was low in Taiwan. There was a significant combined effect of employment status and transcultural marriage on the continuation of breast feeding. Employment is a persistent barrier to continued breast feeding. However, the representativeness of the sam- 
Table 4. Prevalence of breast feeding

\begin{tabular}{|c|c|c|c|c|c|c|}
\hline \multirow[b]{2}{*}{ Breast feeding } & \multirow[b]{2}{*}{ Total } & \multicolumn{2}{|c|}{ Taiwanese mothers } & \multicolumn{2}{|c|}{ Foreign-born mothers } & \multirow[b]{2}{*}{$P$-value } \\
\hline & & Employed & Unemployed & Employed & Unemployed & \\
\hline Total $(=100 \%)$ & 1783 & 972 & 566 & 43 & 202 & \\
\hline \multicolumn{7}{|c|}{ Breast-feeding initiation $^{a}$} \\
\hline Never & $294(16.5)$ & $152(15.6)$ & $92(16.3)$ & $9(20.9)$ & $41(20.3)$ & 0.351 \\
\hline Ever & $1489(83.5)$ & $820(84.4)$ & $474(83.7)$ & $34(79.1)$ & $161(79.7)$ & \\
\hline \multicolumn{7}{|c|}{ Breast-feeding duration (months) ${ }^{\mathrm{b}}$} \\
\hline$<1$ & $748(50.2)$ & $441(53.8)$ & $233(49.2)$ & $18(52.9)$ & $56(34.8)$ & $<0.001$ \\
\hline 1 to $<2$ & $239(16.1)$ & $152(18.6)$ & $64(13.5)$ & $3(8.8)$ & $20(12.4)$ & \\
\hline 2 to $<3$ & $88(5.9)$ & $48(5.9)$ & $25(5.3)$ & $5(14.7)$ & $10(6.2)$ & \\
\hline 3 to $<4$ & $60(4.0)$ & $43(5.2)$ & $13(2.7)$ & - & $4(2.5)$ & \\
\hline 4 to $<5$ & $37(2.5)$ & $24(2.9)$ & $7(1.5)$ & $2(5.9)$ & $4(2.5)$ & \\
\hline 5 to $<6$ & $13(0.9)$ & $6(0.7)$ & $3(0.6)$ & $1(3.0)$ & $3(1.9)$ & \\
\hline $6+$ & $304(20.4)$ & $106(12.9)$ & $129(27.2)$ & $5(14.7)$ & $64(39.7)$ & \\
\hline
\end{tabular}

${ }^{a}$ Values in parentheses are percentages of total.

${ }^{b}$ Values in parentheses are percentages of those who ever breast fed.

pling and the validity of measurement in our study must be considered before reaching any conclusion.

Little documentation of the breast-feeding situation in Asia has been published, ${ }^{22}$ especially of populationbased statistics. Our population-based survey provides some information about developing countries in Asia. This study was designed to obtain the samples that would be representative of all pregnant women in Taiwan; however, further investigation using the 2003 Taiwan National Birth Registration database is warranted to obtain a fuller representative sample. Despite incomplete data for $13 \%$ of subjects and borderline significant differences of preterm deliveries, there was no significant difference of the basic characteristics between the respondents and the non-respondents, such as parents' age, infants' gender, birthweight, or low birthweight. The reason for non-response appeared to be unrelated to our measurement outcomes. In order to reduce recall bias, we only recruited subjects with a completed interview within 6 months after delivery. We measured whether or not they ever breast fed and the duration until they were interviewed. The home interviews using a structured questionnaire by well-trained interviewers were effective in our study to minimise recall bias. Although we chose the women who gave birth from November to December 2003, we believe that the effect of seasonal variation on breast feeding is likely to be minimal.

In general, the South-east Asia region such as Thailand, Singapore and Vietnam; South America such as
Chile, Colombia, Ecuador and Jamaica; Australia; the European region such as Sweden and Denmark, and Austria report a high prevalence rate of breast feeding. Canada, the US, the UK and France show lower initiation of breast feeding compared with the abovementioned countries. The exclusive breast-feeding rate (no food or drink other than breast milk for at least 4 months) was low in most countries, except for Sweden, Australia, Denmark, Egypt, Saudi Arabia and Bolivia. ${ }^{22-25}$

Our study results showed the prevalence of breastfeeding initiation was between $79.1 \%$ and $84.4 \%$. Com-

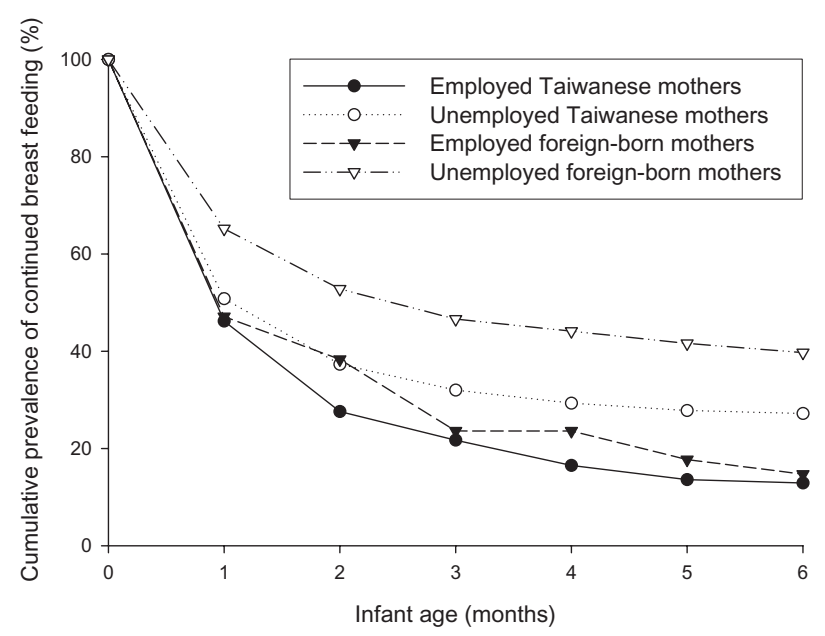

Figure 2. Prevalence of continued breast feeding among the four groups. 
Table 5. Factors related to the initiation of breast feeding in logistic regression models

\begin{tabular}{|c|c|c|c|c|}
\hline Factors & $n(\%)$ & $\begin{array}{c}\text { Crude odds ratio } \\
\qquad[95 \% \mathrm{CI}]\end{array}$ & $\begin{array}{c}\text { Adjusted odds ratio } \\
\text { a } \\
{[95 \% \mathrm{CI}]}\end{array}$ & $P$-value \\
\hline \multicolumn{5}{|l|}{$\begin{array}{l}\text { Combined effect of employment status } \\
\text { and transcultural marriage }\end{array}$} \\
\hline Employed Taiwanese mothers & $972(54.6)$ & 1.00 Reference & 1.00 Reference & 0.637 \\
\hline Unemployed Taiwanese mothers & $566(31.7)$ & $0.96[0.72,1.27]$ & $1.19[0.89,1.60]$ & \\
\hline Employed foreign-born mothers & $43(2.4)$ & $0.70[0.33,1.49]$ & $1.17[0.51,2.68]$ & \\
\hline Unemployed foreign-born mothers & $202(11.3)$ & $0.73[0.50,1.07]$ & $1.24[0.78,1.98]$ & \\
\hline \multicolumn{5}{|l|}{ Maternal education } \\
\hline Elementary school - & $105(5.9)$ & 1.00 Reference & 1.00 Reference & $<0.001$ \\
\hline Junior high school & $259(14.5)$ & $0.56[0.32,0.97]$ & $0.59[0.33,1.08]$ & \\
\hline Senior high school & $1085(60.9)$ & $1.23[0.74,2.06]$ & $1.43[0.77,1.98]$ & \\
\hline University + & $334(18.7)$ & $3.18[1.67,6.07]$ & $3.80[1.81,7.98]$ & \\
\hline \multicolumn{5}{|l|}{ Type of delivery } \\
\hline Caesarean section & $607(34.0)$ & 1.00 Reference & 1.00 Reference & 0.023 \\
\hline Normal spontaneous delivery & $1176(66.0)$ & $1.35[1.04,1.74]$ & $1.36[1.04,1.78]$ & \\
\hline \multicolumn{5}{|l|}{ Preterm delivery } \\
\hline Yes & $148(8.3)$ & 1.00 Reference & 1.00 Reference & 0.066 \\
\hline No & 1635 (91.7) & $1.58[1.05,2.37]$ & $1.48[0.98,2.24]$ & \\
\hline
\end{tabular}

${ }^{\mathrm{a}} \mathrm{A} 10 \%$ change-in-estimate method was used to assess potential confounders. Final model was adjusted for maternal education, type of delivery and preterm delivery.

pared with other countries, it is moderate..$^{22}$ There was no significant difference within the four groups, although the Taiwanese mothers appeared to have a slightly higher rate of breast feeding than foreign-born mothers. The rate of employment by the time they were interviewed was similar for Taiwanese and foreign-born mothers. According to one study in Tai- wan ${ }^{26}$ pregnant women had a high tendency to choose breast feeding ( $88.7 \%$ including mixed feeding). This is consistent with the prevalence rate of breast-feeding initiation in Taiwan mothers.

The most common reason for bottle feeding was related to insufficient or no milk (Table 6), similar to results found in another study. ${ }^{27}$ The reason for insuf-

Table 6. Reasons for never breast feeding

\begin{tabular}{|c|c|c|c|c|c|}
\hline \multirow[b]{2}{*}{ Reasons } & \multirow[b]{2}{*}{ Total } & \multicolumn{2}{|c|}{ Taiwanese mothers } & \multicolumn{2}{|c|}{ Foreign-born mothers } \\
\hline & & Employed & Unemployed & Employed & Unemployed \\
\hline Total $(=100 \%)$ & 294 & 152 & 92 & 9 & 41 \\
\hline \multicolumn{6}{|l|}{ Maternal factors } \\
\hline Insufficient or no milk & $153(52.0)$ & $79(52.0)$ & $42(45.7)$ & $5(55.6)$ & $27(65.9)$ \\
\hline Maternal physical or psychological problems & $28(9.5)$ & $13(8.6)$ & $14(15.2)$ & - & $1(2.4)$ \\
\hline Drugs used during caesarean section & $16(5.4)$ & $7(4.6)$ & $7(7.6)$ & - & $2(4.9)$ \\
\hline Breast problems & $5(1.7)$ & $1(0.7)$ & $3(3.3)$ & - & $1(2.4)$ \\
\hline $\begin{array}{l}\text { For convenience (e.g. return to work, } \\
\text { formula milk is more convenient) }\end{array}$ & $45(15.3)$ & $31(20.4)$ & $10(10.9)$ & $3(33.3)$ & $1(2.4)$ \\
\hline Previous breast-feeding experience & $2(0.7)$ & - & $2(2.2)$ & - & - \\
\hline \multicolumn{6}{|l|}{ Infant factors } \\
\hline Baby refusing the breast & $25(8.5)$ & $12(7.9)$ & $5(5.4)$ & $1(11.1)$ & $7(17.1)$ \\
\hline Mother discharged and baby staying in hospital & $14(4.7)$ & $5(3.3)$ & $7(7.6)$ & - & $2(4.9)$ \\
\hline Baby adopted & $2(0.7)$ & $2(1.3)$ & - & - & - \\
\hline Others & $4(1.4)$ & $2(1.3)$ & $2(2.2)$ & - & - \\
\hline
\end{tabular}

Values in parentheses are percentages. 
Table 7. Factors related to the continuation of breast feeding in multiple Cox regression models

\begin{tabular}{|c|c|c|c|c|}
\hline Factors & $n(\%)$ & $\begin{array}{l}\text { Crude hazard ratio } \\
\qquad[95 \% \mathrm{CI}]\end{array}$ & $\begin{array}{l}\text { Adjusted hazard ratio } \\
\qquad[95 \% \mathrm{CI}]\end{array}$ & $P$-value \\
\hline \multicolumn{5}{|l|}{$\begin{array}{l}\text { Combined effect of employment status } \\
\text { and transcultural marriage }\end{array}$} \\
\hline Employed Taiwanese mothers & $820(55.1)$ & 1.00 Reference & 1.00 Reference & \multirow[t]{4}{*}{$<0.001$} \\
\hline Unemployed Taiwanese mothers & $474(31.8)$ & $0.77[0.67,0.87]$ & $0.76[0.66,0.88]$ & \\
\hline Employed foreign-born mothers & $34(2.3)$ & $0.94[0.65,1.36]$ & $0.91[0.60,1.37]$ & \\
\hline Unemployed foreign-born mothers & $161(10.8)$ & $0.55[0.45,0.69]$ & $0.54[0.42,0.70]$ & \\
\hline \multicolumn{5}{|l|}{ Maternal education } \\
\hline Elementary school - & $85(5.7)$ & 1.00 Reference & 1.00 Reference & \multirow[t]{4}{*}{$<0.001$} \\
\hline Junior high school & $182(12.2)$ & $1.30[0.96,1.78]$ & $1.12[0.80,1.57]$ & \\
\hline Senior high school & $911(61.2)$ & $1.56[1.19,2.04]$ & $1.06[0.76,1.49]$ & \\
\hline University + & $311(20.9)$ & $1.06[0.79,1.43]$ & $0.67[0.47,0.96]$ & \\
\hline \multicolumn{5}{|l|}{ Maternal age (years) } \\
\hline$<20$ & $43(2.9)$ & $1.09[0.78,1.54]$ & $1.12[0.80,1.57]$ & \multirow[t]{3}{*}{0.032} \\
\hline $20-34$ & $1313(88.2)$ & 1.00 Reference & 1.00 Reference & \\
\hline $35+$ & $133(8.9)$ & $0.75[0.60,0.93]$ & $0.76[0.61,0.94]$ & \\
\hline \multicolumn{5}{|l|}{ Mother sleeping with baby at night } \\
\hline No & $289(19.4)$ & 1.00 Reference & 1.00 Reference & \multirow[t]{2}{*}{$<0.001$} \\
\hline Yes & $1200(80.6)$ & $0.62[0.54,0.71]$ & $0.68[0.59,0.78]$ & \\
\hline \multicolumn{5}{|l|}{$\begin{array}{l}\text { Supplemental baby-food feeding } \\
\text { before } 6 \text { months of age }\end{array}$} \\
\hline Yes & $1123(75.4)$ & 1.00 Reference & 1.00 Reference & \multirow[t]{2}{*}{0.001} \\
\hline No & $366(24.6)$ & $0.76[0.66,0.88]$ & $0.78[0.68,0.90]$ & \\
\hline
\end{tabular}

${ }^{\mathrm{a}} \mathrm{A} 10 \%$ change-in-estimate method was used to assess potential confounders. Final model was adjusted for maternal education and age, mother sleeping with baby at night and supplemental baby-food feeding.

ficient or no milk may be related to mothers never establishing breast feeding in the first place. Secondary important reasons for never breast feeding were that it was inconvenient for returning to work and that formula was convenient, especially for mothers employed after delivery. In our data, $90.8 \%$ of women employed in pregnancy returned to work after maternity leave, and just $9.2 \%$ started to work after their delivery. The study showed that employment status was important in the decision of mothers to choose breast feeding. ${ }^{27}$

Mothers commonly initiated breast feeding in our study, but the rate of continuation was low. According to World Health Organization guidelines, the recommended feeding practices for infants are exclusive breast feeding for the first 6 months. ${ }^{28}$ The overall proportion of mothers who breast fed initially and who continued for at least 6 months was only $20.4 \%$, and only $10 \%$ were exclusively breast feeding; this is far less than the breast-feeding goal of the World Health Organisation. The duration of breast feeding for mothers of Taiwan was lower than most Western countries ${ }^{22}$ and Thailand, ${ }_{14}^{14}$ similar to Singapore, ${ }^{23}$ but higher than Hong Kong. ${ }^{29}$ Similar to much of the Asian region, we had a high rate of breast-feeding initiation and a dramatic decrease after the postpartum period..$^{14,23}$ Our results showed that the employed mother ceased breast feeding earlier than those unemployed, whether in Taiwanese or foreign-born mothers. Employment status was associated with early weaning, a situation that also has been reported from other Asian countries such as Thailand ${ }^{14}$ and Singapore..$^{23}$

Our data showed that there seemed to be a significant combined effect of breast-feeding maintenance by employment status and transcultural marriage (Table 7). Overall, unemployed foreign-born mothers seemed to breast feed longer than unemployed Taiwanese mothers; however, there was no significant difference between employed foreign-born and Taiwanese mothers, which is partly due to the small number of employed foreign-born mothers. Planning employment after delivery appeared not to influence the percentage of mothers initiating breast feeding, but it did influence the percentage continuing to breast feed. ${ }^{30}$

In our subjects, foreign-born mothers represented $13.7 \%$ of the total subjects. Most of them were from 
Vietnam (39.6\%), China (35.9\%), Indonesia (13.1\%), Thailand $(1.2 \%)$ and elsewhere $(10.2 \%)$. These figures are similar to national Taiwan statistics. ${ }^{18}$ Overall, the prevalence of breast feeding in most of these countries was higher than Taiwan. ${ }^{31}$ However, we could not explore whether mothers from one particular country account for any of these differences due to small numbers from each country. Nevertheless, the prevalence rate of breast feeding in the first month for mothers born in Taiwan was similar to others.

There are several probable reasons to explain the phenomenon. In traditional Taiwanese custom, women must have 1 month to take a complete rest for postpartum recuperation, known as the traditional Chinese one-month postpartum period (Zuo yuezi). This may be helpful for women to breast feed during the early postpartum period. Other reasons such as maternity leave and the policy of the baby-friendly hospital developed in recent years may contribute to breastfeeding initiation in the early postpartum period. In Taiwan, the mandated maternity leave is 8 weeks, ${ }^{32}$ it is shorter than Ireland (18 weeks), Sweden (14 weeks) and the US (12 weeks). ${ }^{33}$ Though maternal employment status in this study included returning to work after maternity leave or starting to work after delivery, $90.8 \%$ of employed mothers had returned to work after maternity leave. The shortness of maternity leave may be of benefit for initiation but not for continued breast feeding. Furthermore, other policies such as maternity leave to nourish and bring up a baby, and breastfeeding facility in the workplace seem not to increase the continuation of breast feeding for mothers returning to work.

Except for employment status and transcultural effects, high maternal education, normal spontaneous delivery and term delivery (borderline nonsignificant) were the risk factors related to breastfeeding initiation in our results. On the other hand, higher maternal education, older age, sleeping with the baby and no supplemental baby food before 6 months were the factors related to continued breast feeding, consistent with some other studies. ${ }^{8,16,19,25}$

Although breast feeding is common in Taiwan, it is rarely exclusive and usually takes place for a relatively short duration. Returning to work posed a barrier to mothers for maintaining breast feeding. How to overcome the obstacle is an important issue in Taiwan and also in some Western countries. ${ }^{33}$ Not only should we explore how statutory provisions may best be expanded to address the needs of breast-feeding workers, but we should also focus on ways in which workplaces can become more 'breast feeding-friendly' by offering employees flexible work programmes. These include part-time work, job-sharing, phase-back, flexitime, on-site and near-site day care, breast-feeding breaks and facilities. So far, there are some supportive polices for breast feeding for working women, such as maternity leave, to nourish and bring up a baby, and breast-feeding facilities in some workplaces in Taiwan, but it is not common. Educational and promotional strategies for breast feeding must be continued.

\section{Acknowledgements}

This study was based on the data from Taiwan Birth Cohort Study Pilot Database and supported by the grants (BHP-PHRC-92-4 and DOH93-HP-1702) from the Bureau of Health Promotion, Department of Health, Taiwan. We thank the enduring support and assistance from Professor Tung-Liang Chiang, Institute of Health Policy and Management, National Taiwan University College of Public Health, Taipei, Taiwan Professor Meng-Chih Lee, Institute of Medicine, and Professor Hui-Sheng Lin, School of Public Health, Chung Shan Medical University, Taichung, Taiwan; and Professor Bih-Ching Shu, Institutes of Allied Health Sciences, College of Medicine, National Cheng Kung University, Tainan, Taiwan.

\section{References}

1 Leung GM, Lam TH, Ho LM, Lau YL. Health consequences of breast-feeding: doctor's visits and hospitalizations during the first 18 months of life in Hong Kong Chinese infants. Epidemiology 2005; 16:328-335.

2 Chen A, Rogan WJ. Breastfeeding and the risk of postneonatal death in the United States. Pediatrics 2004; 113:435-439.

3 Arifeen S, Black RE, Antelman G, Baqui A, Caulfield L, Becker $\mathrm{S}$. Exclusive breastfeeding reduces acute respiratory infection and diarrhea deaths among infants in Dhaka Slums. Pediatrics 2001; 108:67-74.

4 Oddy WH, Sherriff JL, de Klerk NH, Kendall GE, Sly PD. The relationship of breastfeeding and body mass index to asthma and atopy in children: a prospective cohort study to age 6 years. American Journal of Public Health 2004; 94:1531-1537.

5 Grummer-Strawn LM, Mei Z. Does breastfeeding protect against pediatric overweight? Analysis of longitudinal data from the Centers for Disease Control and Prevention pediatric nutrition surveillance system. Pediatrics 2004; 113:81-86. 
6 Singhal A, Cole TJ, Fewtrell M, Lucas A. Breastmilk feeding and lipopretein profile in adolescents born preterm: follow-up of a prospective randomised study. Lancet 2004; 363:1571-1578.

7 Rasmussen KM, Kjolhede CL. Pregnant overweight and obesity diminish the prolactin response to sucking in the first week postpartum. Pediatrics 2004; 113: $465-471$.

8 Rowe-Murray HJ, Fisher JRW. Baby friendly hospital practices: cesarean section is a persistent barrier to early initiation of breastfeeding. Birth 2002; 29:124-131.

9 Taveras EM, Capra AM, Braveman PA, Jensvold NG, Escobar GJ, Lieu TA. Clinical support and psychosocial risk factors associated with breastfeeding discontinuation. Pediatrics 2003; 112:108-115.

10 Taveras EM, Li R, Grummer-Strawn L, Richardson M, Marshall R, Rego VH, et al. Options and practices of clinicians associated with continuation of exclusive breastfeeding. Pediatrics 2004; 113:283-290.

11 Dodgson JE, Tarrant M, Fong DYT, Peng XH, Choi Hui WH. Breastfeeding patterns of primiparous mothers in Hong Kong. Birth 2003; 30:195-202.

12 Shawky S, Abalkhail BA. Maternal factors associated with the duration of breastfeeding in Jeddah, Saudi Arabia. Paediatric and Perinatal Epidemiology 2003; 17:91-96.

13 Ministry of the Interior, R.O.C. Summary of Survey Results on Women's Living Conditions in Taiwan for the Year of 2002, R.O.C. http://www.moi.gov.tw/stat/index.asp [accessed on 20 April 2007

14 Yimyam S, Morrow M, Srisuphan W. Role conflict and rapid socio-economic change: breastfeeding among employed women in Thailand. Social Science and Medicine 1999; 49:957-965.

15 Whaley SE, Meehan K, Lange L, Slusser W, Jenks E. Predictors of breastfeeding duration for employees of the special supplemental nutrition program for women, infants, and children (WIC). Journal of the American Dietetic Association 2002; 102:1290-1293.

16 Noble S. Maternal employment and the initiation of breastfeeding. Avon Longitudinal Study of Pregnancy and Childhood. Acta Paediatrica 2001; 90: 423-428.

17 Fein SB, Roe B. The effect of work status on initiation and duration of breastfeeding. American Journal of Public Health 1998; 88:1042-1046.

18 Ministry of the Interior, R.O.C. Marriage and Family. http://www.moi.gov.tw/stat/gender/ps03-04.xls [accessed on 30 July 2005].
19 Novotny R, Hla MM, Kieffer EC, Park CB, Mor J, Thiele M. Breastfeeding duration in a multiethnic population in Hawaii. Birth 2000; 27:91-96.

20 Forste R, Weiss J, Lippincott E. The decision to breastfeed in the United States: does race matter? Pediatrics 2001; 108:291-296.

21 Maldonado G, Greenland S. Simulation study of confounder-selection strategies. American Journal of Epidemiology 1993; 138:923-936.

22 World Health Organization. The WHO Global Data Bank on Breastfeeding and Complementary Feeding. 3 September 2003. http:/ / www.who.int/nutrition/databases/infantfeeding/ en/ [accessed on 20 April 2007].

23 Health Promotion Board of Singapore.Prevalence of Breastfeeding in Singapore. 1 March 2005. http:/ / www.hpb.gov.sg/ hpb/default.asp?pg_id=1755 [accessed on 30 July 2005].

24 Chatman LM, Salihu HM, Roofe MEA, Wheatle P, Henry D, Jolly PE. Influence of knowledge and attitudes on exclusive breastfeeding practice among rural Jamaican mothers. Birth 2004; 31:265-271.

25 Callen J, Pinelli J. Incidence and duration of breastfeeding for term infants in Canada, United States, Europe, and Australia: a literature review. Birth 2004; 31:285-292.

26 Huang HC, Wang SY, Chen CH. Body image, maternal-fetal attachment, and choice of infant feeding method: a study in Taiwan. Birth 2004; 31:183-188.

27 Arora S, McJunkin C, Wehrer J, Kuhn P. Major factors influencing breastfeeding rates. mother's perception of father's attitude and milk supply. Pediatrics 2000; 106:67-71.

28 World Health Organization.The Optimal Duration of Exclusive Breastfeeding. Note for the press No. 7. 2 April 2001. http://www.who.int/inf-pr-2001/en/note2001-07.html [accessed on 30 July 2005].

29 Leung GM, Ho LM, Lam TH. Breastfeeding rates in Hong Kong: a comparison of the 1987 and 1997 birth cohorts. Birth 2002; 29:162-168.

30 Visness CM, Kennedy KI. Maternal employment and breast-feeding: findings from the 1988 National Maternal and Infant Health Survey. American Journal of Public Health 1997; 87:945-950.

31 United Nations Children's Fund.The State of the World's Children 2003. http:/ / www.unicef.org/sowc03/tables/ table2.html [accessed on 10 July 2005].

32 Council of Labor Affairs, Executive Yuan Taiwan, R.O.C. Gender Equality in Employment Law. http:/ / equal.cla.gov.tw / law /law01.html [accessed on 3 July 2005].

33 Galtry J. The impact on breastfeeding of labour market policy and practice in Ireland, Sweden, and the UAS. Social Science and Medicine 2003; 57:167-177. 